(c) 2020 The Author/s

This is an open access article under the terms of the CC-BY 3.0 License.

Peer review method: Double-Blind

Date of acceptance: October 18, 2020

Date of publication: November 11, 2020

Review article

DOI: https://www.doi.org/10.47305/JLIA2060080s

\title{
PENITENTIARY INSTITUTIONS AND COVID-19: HOW TO STOP THE VIRUS AND GUARANTEE HUMAN RIGHTS?
}

\author{
Angelina Stanojoska \\ Faculty of Law, University "St. Kliment Ohridski" - Bitola, North Macedonia \\ ORCID iD: https://orcid.org/0000-0002-0587-1222 \\ angelina.stanojoska@uklo.edu.mk \\ Goran Ilik \\ Faculty of Law, University "St. Kliment Ohridski" - Bitola, North Macedonia \\ ORCID iD: http://orcid.org/0000-0003-3501-1386 \\ goran.ilik@uklo.edu.mk
}

\begin{abstract}
Starting the COVID-19 pandemic, physical and social distancing, besides wearing masks and frequent use of disinfectant, was and still is the most important preventive measure in stopping the spreading of the new coronavirus. Penitentiary institutions, especially the crowded ones, became a hard place to manage in stopping the infections. Why? Because these institutions are the ones where there is even more need to balance health protection with human rights. Using medical isolation and quarantine in the process of prevention of infections with SARS-COV-2 virus, is complicated as result of the use of punitive solitary confinement as disciplinary sanction. The paper analyses the possible methods of protection of prisoners' health during COVID-19 pandemic with parallel protection and respect of their basic and guaranteed human rights.
\end{abstract}

Keywords: COVID-19; Human Rights; Penitentiary Institutions; Prisoners 


\section{INTRODUCTION}

Historically, pandemics and epidemics are no unknown to humanity. Zoonotic pathogens spread among humans for a long time. In the $20^{\text {th }}$ Century, there were the influenza pandemics A/H1N1 in 1918 to 1919, A/H2N2 in 1957, A/H3N2 in 1958, and in the 21st Century - SARS-CoV-1 in 2003,A/H1N1pdm in 2019, and MERS in 2012, and the SARS-CoV-2 from December, 2019 (Barnert and Ahalt, 2020).

The new coronavirus disease (COVID-19) was for the first time reported in Wuhan, China, and afterwards until 13 October 2020, there are 38.287,154 confirmed cases and 1.088,856 confirmed deaths (Worldometer 2020). With so many cases and the especially fast spreading of the novel coronavirus, countries started to use restrictive and precautionary measures. Because of the mode of transmission (droplet and contact, and in some circumstances and settings, also an airborne transmission) physical distancing and isolation of infected are the most important measures in mitigating the path of the virus (Wang et al. 2020).

As many other pathogens, also SARS-CoV-2 is very dependent on the complex way of human interaction and behavior. Custodial institutions, such as penitentiary institutions are with high risk of infections and spreading of the virus, especially because of the incarcerated communities, in most cases overcrowding and insufficient sanitation, poor ventilation and inadequate healthcare. There is insufficient number of single rooms in penitentiary institutions, and incarcerated communities live in larger groups, in cohorts and in confined spaces with limited time outside of the institution (Kinner et al. 2020; CDC 2020).

The SARS-CoV-2 has the ability to survive for prolonged periods on materials and those materials include nonporous and metallic surfaces that are complicating disinfection practices. The complex patterns of human contacts in penitentiary institutions, in most cases complicate the process of repeated disinfection and decontamination of surfaces in those institutions (Franco-Paredes et al. 2020).

The situation inside the Princess Diamond Cruise, that was berthed in Yokohama port, Japan (03/02 - 01/03/2020), has shown that the novel coronavirus spreads really rapidly inside closed environment and among large crowds. Among 3711 passengers, there were 696 infected cases and 9 deaths (Mizumoto and Chowell 2020).

Having higher basic reproduction number, the SARS-CoV-2 in comparison to the influenza virus $\mathrm{A} / \mathrm{H} 1 \mathrm{~N} 1$, is more dangerous in its transmission, especially by patients with mild symptoms and those with asymptomatic infection (in up to $20 \%$ of cases) (Li et al. 2020). Achieving an R0 less than 1 in penitentiary institutions is really limited, because of large presence of individuals in closed spaces, no possibility for social distancing, and limited possibilities for hygiene and disinfection. The paper elaborates the complexity and limited options of prevention of novel coronavirus infections inside penitentiary institutions, especially in overcrowded places. 
But is also important to have in mind during measures of prevention of infection are the basic healthcare needs of prisoners, and their basic human rights. The restrictive measures must not be used as sanctions, must not threaten prisoners' mental health, and very important, they should know the difference, and goals of isolation (in cases of infections) compared to solitary confinement.

\section{COVID-19 RESTRICTIVE AND PROTECTION MEASURES IN PRISONS: WHERE IS THE PROBLEM AND WHAT HAS BEEN DONE?}

Populations which are inside the criminal justice system have an increased

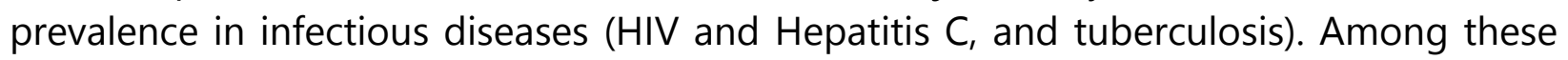
populations there are disparities in social determinants, that are affecting groups which are mostly incarcerates, such as racial minorities, individuals with unstable housing, individuals with mental illness (inside institutions there is high prevalence of such health conditions), individuals with substance use disorders (Akiyama et al. 2020).

Penitentiary institutions and other custodial settings are characterized with poor ventilation conditions, living settings where prisoners are living close to each other, which increase the possibility of person to person virus transmission. Also, what makes prisoners even more vulnerable to the virus are the poorer hygiene conditions, worse health conditions and weaker immune system, which results in higher number of comorbid conditions (WHO Regional Office of Europe 2020). There are around 10 million people in prisons worldwide; they are population with serious prevalence of physical and psychiatric morbidity and vulnerability, and results in suicide and premature death (Gulati et al. 2019). For a successful operationalization and managing the pandemic inside penitentiary institutions, there are three levels, which should be addressed: first, the virus should be delayed from entering inside prisons, as much as possible; if the virus is already inside, it spread should be controlled; and prisons should be prepared to deal with the virus and the burden of the disease (Akiyama et al. 2020).

Starting March 2020, when restrictive measures were imposed in most of the European countries, penitentiary institutions and prison systems were under continuous pressure to stop the spread and manage the impact that COVID-19 has inside prisons, and to keep prisoners and staff safe. With the second wave happening at the moment, there are many possibilities for, maybe, stricter measures, and it becomes even harder to motivate staff in managing the situations, but also, it is even harder to prevent riots among prisoners (EUROPRIS 2020). Closed communities in prisons, present a challenge and suitable ground for rapid spread of the novel coronavirus, especially of prison overcrowding (Gulati et al. 2020). When a case of infected person is found inside the penitentiary institution, then all prisoners and staff should be screened. Those with abnormal symptoms should be recorded and examined. Close contacts should be tracked and isolated. Isolation should be used with precaution. Why? 
Because hallmarks of solitary confinement (social isolation, physical idleness, and sensory deprivation) lead to psychological suffering and trauma with immense proportions and could lead to self-harm, violence, and suicide, even after short periods of time (Haney 2018). What has also been perceived as a problem is the not reporting of symptoms, because of the fear of being moved to isolation.

But, there are main differences between medical isolation and quarantine, and solitary confinement. Namely, the purpose of the first one is to reduce the spread of the disease, and to the second one is punishment. The length of medical isolation is until there is evidence that the person is no longer contagious; the quarantine until the person is free from infection; and the length of solitary confinement is determined by security staff. The conditions in medical isolation and quarantine are sanitary (toilet, sink, soap), adequate light, ventilation, comfortable temperature; and in solitary confinement there is either little or no natural light, there are unsanitary conditions, poor temperature, there is frequent use of force and chemical agents. In medical isolation and during quarantine, prisoners have free access to media, reading materials, nutritious meals, opportunities for going outwards, have free access to phone and video calls, email, etc. On the other hand, there are major restrictions or complete bans, no personal property, or TV, and other media; and also with major restrictions or complete ban with family contact, visitors, phone calls, emails, etc. (Cloud et al. 2020). Also, restrictive measures, such as visiting arrangements, also, heightened the feeling of isolation. There were cases of prisoners' deaths as result to COVID-19 restrictions and riots because of the restrictions (Euronews and AFP 2020; The Guardian 2020).

What measures should be implemented in direction to prevent the spread of the new coronavirus, but also to act in accordance with international documents (the right to parity of medical care and the right to bodily integrity despite restrictions in their liberty (Mandela Rules, UN), and to respect basic human rights?

Even in times of pandemic, the fundamental safeguards outlined in the Mandela Rules must be respected. Importantly, confinement should be limited to 22 hours or more a day without a meaningful human contact as an exceptional measure, and never beyond a maximum of 15 consecutive days; external inspection bodies and legal advisors to prisoners must have access to prisons; health decisions must be made only by medical personnel; and prisons should abstain from total suspending of family contacts together (UNODC 2020).

The World Health Organization prepared a checklist intended to be used by policy-makers and prison administrators in order to evaluate their level of preparedness to prevent and control the spread of the novel coronavirus inside prisons and other places of detention. 


\section{What are the principles and human rights considerations inside penitentiary institutions during COVID-19 pandemic?}

The WHO underlines the importance of having the same health care standards inside prisons as they are available in the outside community. Such conditions are necessary in order to avoid any kind of discrimination of prisoners. On site there is need of adequate measures in preventing stigmatization or marginalization of individuals or groups who are considered to be infected or are potential carriers of the virus (WHO 2020).

Administration should have in consideration the possibility for increased need for emotional and psychological support of prisoners, the necessity of awareness raising and sharing of information, and stable and continuous contact with family members (WHO 2020).

Prisoners who are subjected to isolation should be informed of the reason and should be given the possibility to notify a third party. These prisoners should be protected during isolation from any kind of ill-treatment and should have human contacts in appropriate way (virtual or audio) (WHO 2020).

The Council of Europe has issued a Statement of principles relating to the treatment of persons deprived of their liberty in the context of the coronavirus disease (COVID-19) pandemic in order to ask the need of balance between the imperative to fight COVID-19, but also the need to protect prisoners and respect their basic human rights. Even in these times of pandemic, there are limits and important principles of human rights and democratic societies. All actors of the criminal justice system should not forget the absolute nature of prohibition of torture and inhuman and degrading treatment, and should implement the following steps:

- All penitentiary institutions should undertake all possible actions in order to protect health and safety of prisoners and other individuals deprived of their liberty, and of all staff inside penitentiary institutions;

- During protection of health and safety, all WHO guidelines, national health and clinical guidelines should be respected and implemented on site;

- Staff should have all professional support, and health and safety instructions and training;

- All used restrictive measures taken to prevent the COVID-19 should have legal basis, and respect human dignity. Every individual deprived of his/her liberty should receive information for the actions taken in language he/she understands;

- Because of overcrowding inside prisons and other places of detention, states should undertake measures of decreasing the occupancy rate;

- All prisoners should receive additional psychological help during the COVID-19 restrictions. Health care should be provided to all individuals, but specially to vulnerable groups and individuals with pre-existing medical conditions; 
- Although as part of restrictive measures some of the non-essential activities have been suspended, the fundamental rights, even during pandemic, must be fully respected. Prisoners must have the right to maintain adequate personal hygiene, and the right to daily access to the open air. Furthermore, when visits are restricted or limited, there must be use of alternative means of communication (phone calls, or virtual visits);

- When a prisoner has been isolated, because he is either infected or suspected to being infected, must have meaningful human contact every day;

- Individuals deprived of their liberty should have access to fundamental safeguards against ill-treatment at all times and all circumstances;

- Monitoring bodies should have access to penitentiary institutions and other institutions for detention, even to places where individuals are kept in quarantine (Council of Europe 2020).

\section{How the occupancy rate has been decreased (in some EU countries)?}

Because the new virus spreads easily in overcrowded places, measures should be undertaken to reduce prison population, using alternative measures and early release to low-risk offenders.

In direction to protect prisoners, and open possibilities for physical distancing among prisoners, every country should reduce the occupancy rate in prisons. Why? There will more space created among prisoners in one wing or unit, and second, the creation of additional space will be used to adapt parts as medical wings.

The highest prison population (more than 250 prisoners per 100000 inhabitants) is found in Russian Federation and in Turkey, followed by Georgia, Lithuania and Azerbaijan (more than 200 prisoners per 100000 inhabitants), and lowest (less than 80 prisoners per 100000 inhabitants) in the Scandinavian countries (Aebi and Tiago 2020) (Figure 1).

Which measures were used to decrease the occupancy rate inside penitentiary institutions? (Aebi and Tiago 2020).

- One of the measures used in decreasing the occupancy rate is the postponing of the start of prison sentences for up to six months. Short-term sentences (up to 6 months) were suspended for several months. The conversion of unpaid fines to prison sentence were suspended and postponed.

There is early release of prisoners who had two to six months remaining from their sentence. What should be pointed out is that although released prisoners are going back to society and will have contacts with other people, they are lower risk to the public (in contacts, and because of the nature of their crime), but if they stay in the institution will be a significant risk in terms of the pandemic. Of course, perpetrators of violent crimes are not part of the early release measures. 
Those prisoners, who were on leave when the restrictive measures were imposed and the pandemic started, were allowed to extend their leave for a longer period of time, in order to prevent an infection with their re-entry into the penitentiary institution (in Ethiopia - the President granted pardon to more than 4000 prisoners, mostly with a maximum sentence of three years and to those approaching to their release; in the USA - four states decided to release hundreds of pretrial detainees and prisoners sentenced for minor crimes; in Germany - the state of North-Rhine Westphalia 1000 prisoners have been released; the Islamic Republic of Iran temporarily released 85000 prisoners; Afghanistan released 10000 prisoners (women, juveniles, prisoners with medical conditions, and prisoners aged 55 and above) (UNODC, 2020));

- Many of the short sentences or the remaining sentences (of longer convictions) and even pre-trial detention, were replaced with non-custodial measures (home detention, reporting to the police regularly, regular phone calls, video calls, etc.);

- In cases when early release and use of non-custodial measures did not achieve the desired results in decreasing occupancy rate, transfers of small groups of prisoners were used to alleviate the pressure on a single institution or state region. Also, there is a possibility for prison expanding in capacity, and use of new wings as emergency parts for medical isolation.

The countries that adopted the preventive measure of early release of prisoners can be divided into two groups: countries that had already have a low incarceration rate (the Scandinavian countries and the Netherlands), and countries that had a high level of infections (Spain, Italy and France) (Aebi and Thiago 2020) (Figure 2).

- In penitentiary institutions where conditions on site allowed such steps, have provided single cells accommodation, because of the impossible mission to maintain physical distance inside a cell which is shared.

All penitentiary institutions should move to single-cell accommodation of prisoners with in cell-sanitation. New prisoners should be screened on reception (with focus on history of travel and symptoms). Infected prisoners should be transferred to medical facilities (there should be local arrangements between hospitals and penitentiary institutions). Non infected prisoners should receive ongoing physical health and mental healthcare, especially because these are risk factors for serious symptoms development and deadly outcome. Prisoners should receive (in needed) psychological intervention in cases of anxiety and worries regarding the illness. And at the end, but not less important, prisoners should have the possibility to use new treatments of COVID - 19, and should have access to vaccines when they are going to be available (Gulati et al. 2020). 
Journal of Liberty and International Affairs | Vol. 6, No. 2, Supp. 1, 2020 | elSSN 1857-9760 Published online by the Institute for Research and European Studies at www.e-jlia.com

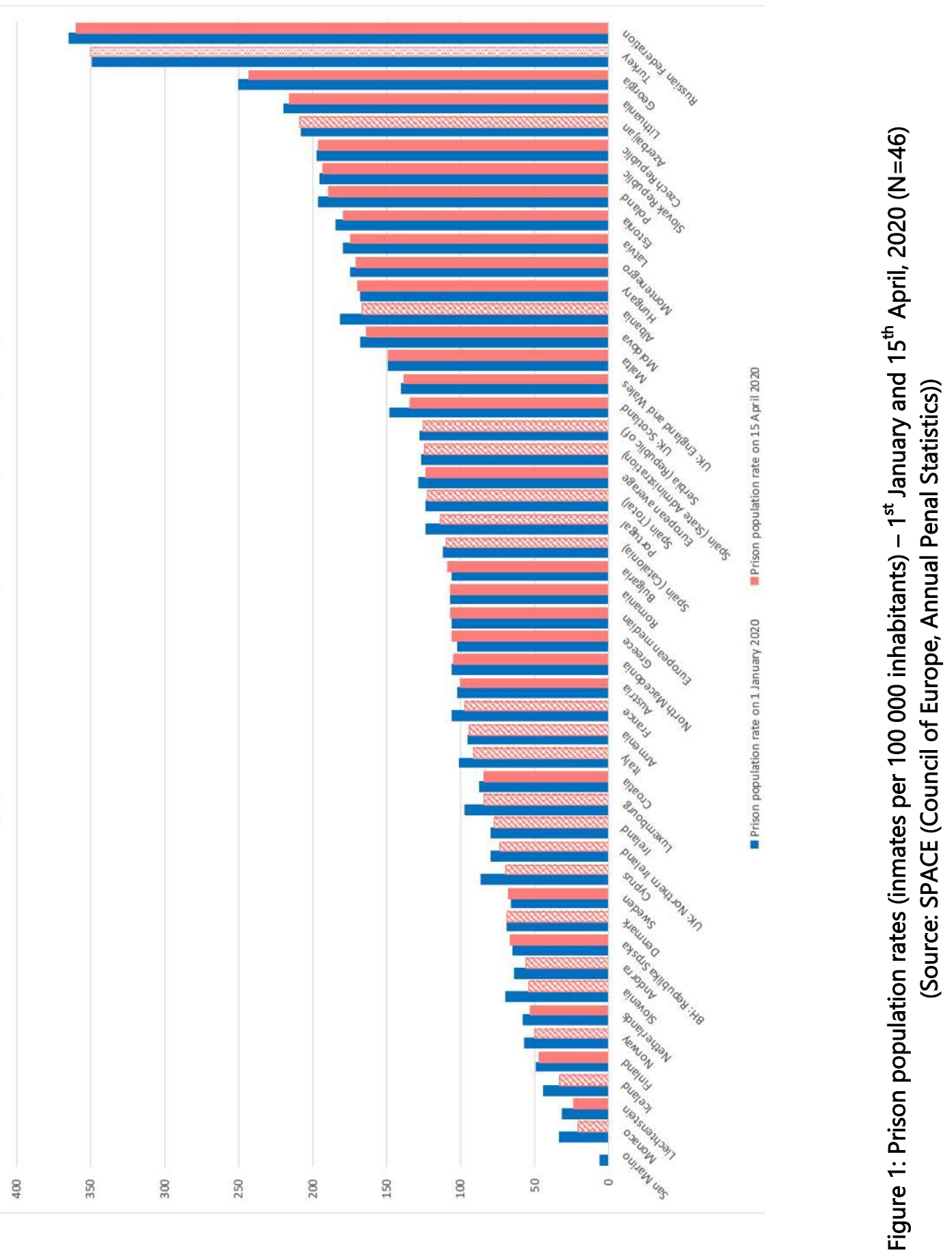

$\stackrel{(c) E Y}{2}$ ○ doi 
Journal of Liberty and International Affairs | Vol. 6, No. 2, Supp. 1, 2020 | elSSN 1857-9760

Published online by the Institute for Research and European Studies at www.e-jlia.com

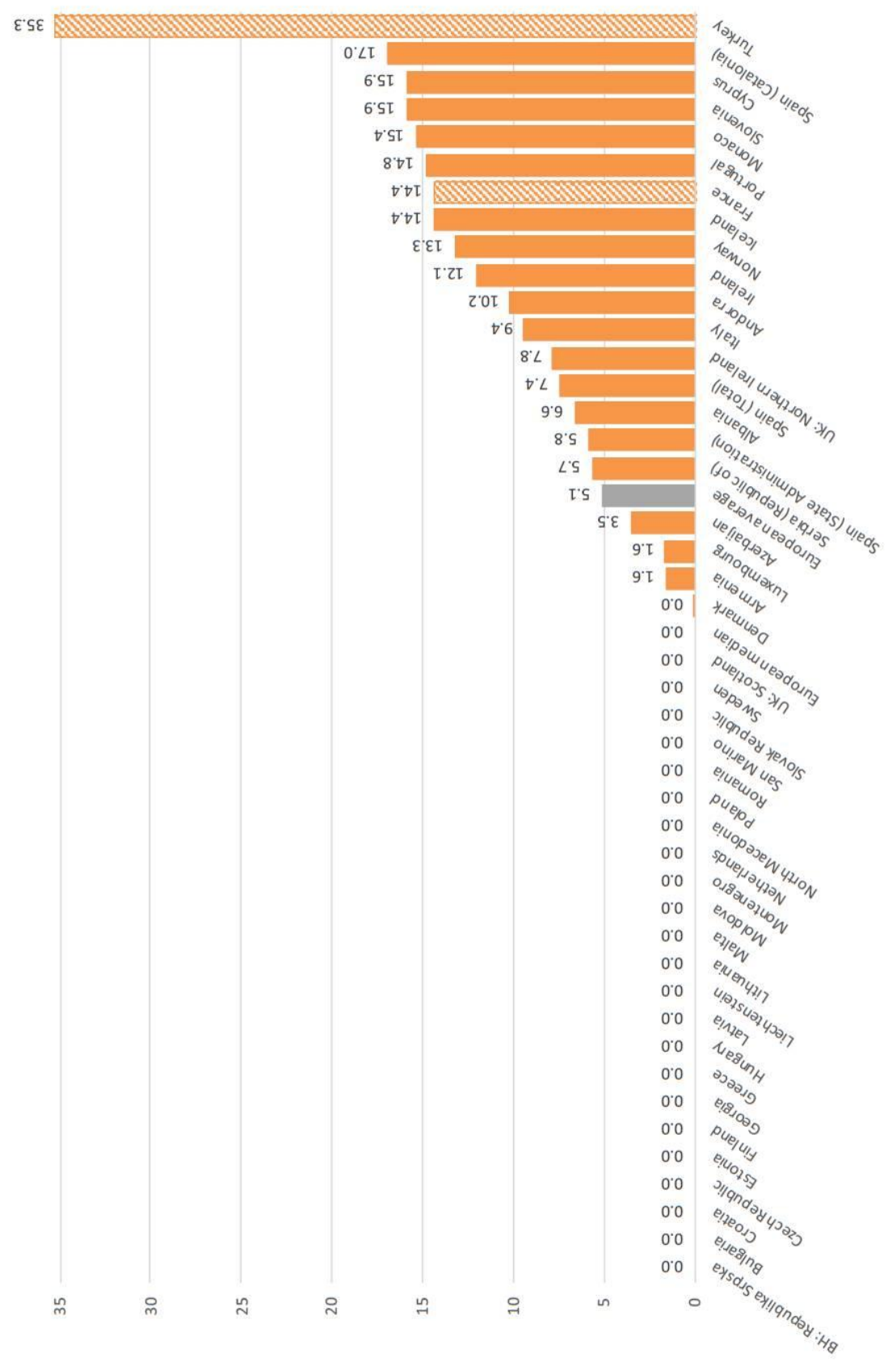

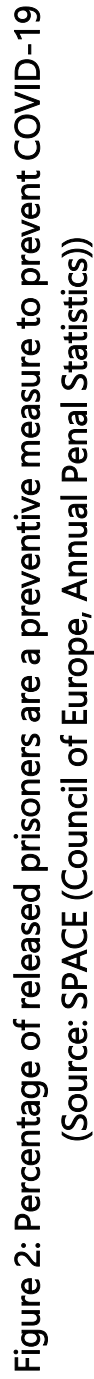




\section{How to keep life 'normal' inside penitentiary institutions?}

The negative impact of the pandemic situation on prisoners has been the lack of family visits, which after being restored have been undertaken under strict protocols and measures of protection to prisoners (EUROPRISS 2020). Also, there are possibilities for video - conferencing, especially in cases of communication between imprisoned parents and their children. Using online tools, parents were able to read bedtime stories to their children, and have the possibility to spend more time with them. This measure should be used even after the end of the pandemic, but of course as additional possibility of inperson visits, which are irreplaceable. Virtual visits offer possibilities for contact with more family members compared to physical visits during which number of persons is limited. How to keep life "normal" and guarantee prisoner's basic rights? (EUROPRISS 2020).

- There are pre-visit health checks for visitors, such as temperatures' measure before entering the premises and filling out forms about their health. In cases when visitors have symptoms, or they have been recently tested as positive to the novel coronavirus, they are not allowed to enter the premises;

- The need for physical distance between people asked for changes inside meeting rooms, in accordance to circumstances, and climate. Penitentiary institutions with larger rooms, changed the distance between visit desks, have visit cabins, or are organizing visits outdoors;

- Visitors are asked to wash and/or to disinfect their hands before the start of their visit, or are asked to wear gloves and face masks. Consumption of food and drinks are not allowed, exchange of laundry, and after the end of the visit, premises are disinfected;

- There are distancing regulations, with keeping two meters' distance and/or using screen partitions. The authorities have the right to interrupt the visit, when the prisoner or his/her visitor, do not comply with these regulations;

- Also, the number and the duration of visit are limited, especially because of the need of more staff in organizing and controlling the visits. There is limitation on the number of visitors (one or two people at the same time), time limitation (3060 minutes), and/or limitation of the number of visits per week;

- During visitation, priority is given to direct family members, especially underage children.

Every measure that could help stop the spread of the novel coronavirus, or flatten the curve, is important, but what is important is those measures to guarantee basic human rights and to prevent any kind of ill-treatment to prisoners. There should be balance between the importance of protection of public health and the protection of human rights and human dignity of individuals deprived of their liberty. 


\section{CONSLUSION}

The novel zoonotic pathogen has showed its persistence in every climate conditions, every part of the Earth, being very contagious, forced humans everywhere to start living in an, until now, strange and different way. There should be physical distance between us, no large groups, especially inside, we should wear masks, not shake hands, do not hug, try to work from home, visit virtually our family and friends.

Such characteristics of the SARS-CoV-2and past pandemics, and epidemics, have shown that penitentiary institutions and prisoners are in higher danger of being infected. Such great risk is result of inability to quarantine, practice social and physical distancing, and some prisons are overcrowded.

A lot of work should be done in order to stop the entrance of the virus inside institutions where individuals deprived of their liberty, and in cases it enters, then even more. Isolation and quarantine, and solitary confinement, are in many cases mixed by prisoners, which is one of the reasons why they should receive all necessary information regarding the virus, symptoms and ways of treatment, so they could understand what isolation and quarantine mean and why are they important in the fight against the novel coronavirus. Administrations should secure that these measures will not be used as sanctions towards prisoners, and that there will balance between human rights and dignity of the prisoners, the absolute forbiddance of ill-treatment and other forms of inhuman and degrading treatment, and the steps and measures to stop the spread of the virus and flatten the curve.

Even in normal times, when there is no pandemic, prisons should not be overcrowded and states should use non-custodial measures as much as they can. These sanctions are of essential importance in decreasing occupancy and prison population rates, but also in the process of resocialization of primary offenders and offenders who have committed crimes that are less serious. If these steps were undertaken years before COVID-19, today we would not have to find fast solutions to decrease occupancy rates. On the other hand, many countries still have poor living conditions inside penitentiary institutions, which include many other connected problems, such as no or poor ventilation conditions, old buildings, ruined toilets and baths.

All of these do not allow hygiene on higher level, which together with masks and physical distance is the main mean in the fight against the virus. Such conditions open possibilities for fast spread of the virus and breach of the guaranteed basic human rights of prison population. 


\section{REFERENCES}

1. Aebi, Marcelo F. Melanie, M. Tiago. 2020. "Prisons and Prisoners in Europe in Pandemic Times: An evaluation of the short-term impact of the COVID-19 on prison populations". Council of Europe - SPACE (Council of Europe Annual Penal Statistics);

2. Akiyama, Matthew J. Anne, C. Spaulding. Josiah, D. Rich. 2020. "Flattening the Curve for Incarcerated Populations - COVID-19 in Jails and Prisons". The New England Journal of Medicine. 1-3;

3. Apostolo, Joana. Rita Martins. Pedro, das Neves. 2020. COVID-19 Pandemic Response: Fighting the invisible threat in prisons. Innovative Prison Systems.;

4. Barnert, Elizabeth. Cyrus, Ahalt. Brie, Williams. 2020. "Prisons: Amplifiers of the COVID-19Pandemic Hiding in Plain Sight" AJPH. 1-3;

5. Cloud, David H. Cyrus, Ahalt. Dallas, Augustine. David, Sears. Brie, Williams. 2020 "Medical Isolation and Solitary Confinement:Balancing Health and Humanity in US Jails and PrisonsDuring COVID-19". J Gen Intern Med.;

6. European Centre for Disease Prevention and Control. 2020. Infection prevention and control and surveillance for coronavirus disease (COVID-19) in prisons in EU/EEA countries and the UK;

7. European Committee for the Prevention of Torture and Inhuman or Degrading Treatment or Punishment. 2020. Statement of principles relating to the treatment of persons deprived of their liberty in the context of the coronavirus disease (COVID-19) pandemic;

8. European Organization of Prison and Correctional Services. 2020. Overview of European prison services' responses to the COVID-19 crisis;

9. European Organization of Prison and Correctional Services. 2020.Reducing Overcrowding | EuroPris COVID-19 pandemic fact sheet.;

10. Franco-Paredes, Carlos. Katherine, Jankousky. Jonathan, Schultz. Jessica, Bernfeld. Kimberly, Cullen. Nicolas, G. Quan. Shelley, Kon. Peter, Hotez. Andres, F. HenaoMartinez. Martin, Krsak. 2020. "COVID-19 in jails and prisons: A neglectedinfection in a marginalized population". Neglected Tropical Diseases. 14 (6): 1-4;

11. Gulati, Gautam. Colum, P. Dunne. Brendan, D. Kelly. 2020. "Prisons and the COVID-19 Pandemic". Irish Journal of Psychological Medicine. 1-5;

12. Hawks, Laura. Steffie, Wollhandler. Danny, McCormick. 2020. "COVID-19 in Prisons and Jails in the United States". JAMA Internal Medicine. 1-2;

13. The AIRE Centre. 2020. COVID-19 and the Impact on Human Rights.;

14. UNAIDS. 2020. Rights in the time of COVID-19: Lessons from HIV for an effective, community-led response.; 
15. UNODC, WHO, UNAIDS and OHCHR Joint Statement On Covid-19 In Prisons and Other Closed Settings. 2020;

16. UNODC. 2010. Handbook on strategies to reduce overcrowding in prisons. UN: New York;

17. UNODC. 2017. Assessing compliance with the Nelson Mandela Rules. UN: New York;

18. UNODC. 2020. "COVID-19 preparedness and responses in prisons";

19. Wang, Jiao. Wenjing, Yang. Lijun Pan. John, S. Ji. Jin, Shen. Kangfeng, Zhao. Bo, Ying. 2020. "Prevention and control of COVID-19 in nursing homes, orphanages, and prisons". Environmental Pollution. 266: 1-6;

20. WHO. 2020. Preparedness, prevention and control of COVID-19 in prisons and other places of detention. WHO Regional Office in Europe: Copenhagen;

21. Worldometers. 2020. "Coronavirus Update (live)". Last modified 02 November, 2020. https://www.worldometers.info/coronavirus/. 